\title{
Evaluation of cultural techniques for isolating Campylobacter pyloridis from endoscopic biopsies of gastric mucosa
}

\author{
CS GOODWIN, ${ }^{*}$ ED BLINCOW, ${ }^{*}$ JR WARREN, $†$ TE WATERS, $\ddagger$ CR SANDERSON, \\ L EASTON $\ddagger$
}

From the Departments of ${ }^{*}$ Microbiology, $†$ Pathology, and $\ddagger$ Gastroenterology, Royal Perth Hospital, Perth, Western Australia

SUMMARY One hundred and three gastroscopic biopsies from 80 patients were cultured for Campylobacter pyloridis and studied histologically. Active chronic gastritis, as shown by the presence of polymorphonuclear leucocytes, was diagnosed in 51 biopsies and $C$ pyloridis was found in 47. Sixteen gastric biopsies showed normal histology (no inflammation); $C$ pyloridis was detected in only one of these, and a second biopsy taken from this patient at the same time showed active gastritis. Biopsies could be kept at $4^{\circ} \mathrm{C}$ for five hours without loss of viability of $C$ pyloridis. An inoculum made by grinding the biopsy in a ground glass grinder consistently gave a much heavier growth of $C$ pyloridis than one made by mincing the specimen. The campylobacter supplement ferrous sulphate, sodium metabisulphite, sodium pyruvate (FBP) (Oxoid) was inhibitory for some isolates; the inhibitory component was found to be sodium metabisulphite. Contaminants, but not $C$ pyloridis, were inhibited by the incorporation of vancomycin $6 \mathrm{mg} / \mathrm{l}$, nalidixic acid $20 \mathrm{mg} / \mathrm{l}$, and amphotericin $2 \mathrm{mg} / \mathrm{l}$, but higher concentrations inhibited $C$ pyloridis. Undried plates kept in a plastic container at room temperature for up to two weeks were as satisfactory as freshly poured plates for the isolation of $C$ pyloridis.

Spiral bacteria were cultured from endoscopic biopsies of gastric antral mucosa at this hospital during 1982.' The name Campylobacter pyloridis has been proposed for these bacteria, ${ }^{2}$ which may be important in the aetiology of gastritis and peptic ulcer. During the study spiral bacteria were seen histologically in 58 of 100 biopsies but were cultured from only 11. In 1984 McNulty and Watson, working in a specialist laboratory, reported the presence of spiral bacteria in great abundance in Gram stained material from endoscopic biopsies. They were, however, "struck by the paucity of colonies that appeared on the culture plates." Since 1982 we have improved our culture techniques, and colony densities now closely match the number of bacteria seen on microscopy. This study was carried out in 1984 to evaluate a range of culture techniques for isolating $C$ pyloridis from endoscopic biopsies.

\section{Material and methods}

All patients referred to the gastroenterological unit

Accepted for publication 11 June 1985 at this hospital and from whom an endoscopic biopsy had been taken from the upper gastrointestinal tract were eligible for the study. Between March and August 1984, 103 matching pairs of biopsies were obtained for culture and histology were obtained from 80 patients. The group comprised 41 men aged 26-90 (mean 59) and 39 women aged 23-85 (mean 62). Ninety pairs of biopsies were obtained from the stomach, 81 from the antrum and nine from the body. In addition, eight biopsies were taken from the oesophagus and five from the duodenum. In the antrum the biopsies were taken at a distance from any focal lesion such as a peptic ulcer.

The first 19 specimens for microbiological culture were transported to the laboratory in $2 \mathrm{ml}$ isotonic saline. As such fluid could have caused dissolution of the mucus layer under which the bacteria are in close contact with the mucosa, with subsequent loss of the bacteria into the fluid, a small amount of hypotonic fluid $(0.5 \mathrm{ml}$ of $20 \%$ glucose $)$ was used as the transport medium for the remaining specimens. The biopsies were kept at $4^{\circ} \mathrm{C}$ until they were inoculated on to solid media. The time until inoculation 
was recorded. Ten biopsies were divided, and one part was immediately processed for culture while the other part was kept at $4^{\circ} \mathrm{C}$ for varying lengths of time to determine the effect of delay on the isolation of $C$ pyloridis.

PREPARATION OF GRAM STAIN AND INOCULUM A portion of each biopsy was used to make a smear which was subsequently stained by Gram's method. The remainder was cultured. The first 31 specimens were minced with two sterile knives to prepare the inoculum. The other specimens were ground in 0.3 $\mathrm{ml} 20 \%$ glucose with a ground glass grinder. Three drops of suspension were obtained, and one drop was used as the inoculum. To determine which method yielded the largest number of colonies 10 specimens were divided; one half was processed by mincing and the other half by grinding, with inoculation on to brain-heart infusion agar with $10 \%$ horse serum, $0.25 \%$ yeast extract, and $0.4 \%$ tetrazolium chloride to visualise the colony densities.

\section{COMPOSITION OF SOLID MEDIA}

Before this study we had found that abundant growth of $C$ pyloridis was obtained on freshly poured brain-heart infusion agar base (Oxoid) containing $7 \%$ horse blood and Isovitalex $1 \%$ (BBL Microbiology systems), with vancomycin $3 \mathrm{mg} / \mathrm{l}$ and nalidixic acid $10 \mathrm{mg} / \mathrm{l}$. All specimens were inoculated on to this standard medium. Various other media were inoculated in parallel to answer the following questions concerning primary isolation of $C$ pyloridis: must the medium be fresh; is lysed blood better than whole blood; is Campylobacter FBP (Oxoid) supplement useful; and what are the best concentrations of inhibitory antibiotics? Plates kept at room temperature in a closed plastic box for six to 19 days were used for 36 specimens. Lysed blood medium was used for 30 specimens and whole blood with FBP supplement for a further 20 specimens; when failures occurred the individual components of FBP were tested to find which inhibited $C$ pyloridis. Medium without antibiotics was inoculated in parallel, and, in addition, higher concentrations of antibiotics were used in various media.

\section{INCUBATION ATMOSPHERES}

One plate from each specimen was incubated in a "preferred" atmosphere obtained by evacuation of an anaerobic jar to $220 \mathrm{~mm} \mathrm{Hg}$ and replacement with an anaerobic gas mixture $(10 \%$ carbon dioxide, $10 \%$ hydrogen, and $80 \%$ nitrogen) giving an atmosphere of $5 \%$ oxygen, $7 \%$ carbon dioxide, $8 \%$ hydrogen, and $80 \%$ nitrogen. Two other atmospheres were tested in parallel: a standard campylobacter gas mixture ( $8 \%$ carbon dioxide, $7 \%$ oxygen, and
$85 \%$ nitrogen) for 46 specimens and a carbon dioxide incubator ( $7 \%$ carbon dioxide, $20 \%$ oxygen, and $73 \%$ nitrogen) for 33 specimens; water was placed in the bottom shelf, giving a humidity of $98 \%$ when measured by a Vaisala machine. We had previously determined that $C$ pyloridis failed to grow in another carbon dioxide incubator with similar percentages of carbon dioxide and oxygen, but with a humidity between 94 and $98 \%$, suggesting that for primary isolation $C$ pyloridis required a constant के atmosphere of at least $98 \%$ humidity. Sections were $\vec{\circ}$ stained with haematoxylin and eosin and WarthinStarry stain for spiral bacteria and were graded for gastritis as described by Marshall and Warren. ${ }^{\prime}$ Gradings were based on the type of inflammatory cells present. Grades 0 and 1 signified normal. $\omega_{\infty}^{\omega}$ Grade 2, or "chronic gastritis," indicated inflammation with no increase in polymorphonuclear leucocytes. Grade 3, or "active gastritis," was used to indicate an increase in polymorphonuclear leucocytes, usually an intraepithelial infiltration. ${ }^{4}$

\section{Results}

DISTRIBUTION OF C PYLORIDIS IN THE GASTRIC MUCOSA

Most histological sections showed an uneven dise tribution of bacteria, often quite patchy. From 2 patients in whom bacteria were found, two or move biopsies had been taken from the stomach; 17 patients $(62 \%)$ showed a different concentration of spiral bacteria on the two specimens, and in two cases the bacteria were not seen on one or more specimens. One of these patients showed chronic $\bar{a}$ gastritis with gross atrophy and intestinal metaplasia in two biopsies, although no bacteria were seen, but a third biopsy, taken from an area adjacent to a gastric ulcer, showed active gastritis, no metaplasia, and numerous spiral bacilli. The second patient $:$ showed normal antral mucosa with occasional bacteria. Three gastric polyps from this patient were $\delta$ also biopsied; all showed active gastritis, although bacteria were not seen on two but were numerous $\mathrm{O}$ on the third. Biopsies for histology and culture were taken as matching pairs, yet in 11 cases $C$ pyloridis was found in only one of the pair, possibly due to the irregular distribution.

C pyloridis was cultured from 48 of the 103 biop- $N$ sies, and in another six specimens spiral bacteria N were seen with the Gram stain but not on culture. $\sigma$ Spiral bacteria were seen in 55 biopsies, and in another five biopsies $C$ pyloridis was either seen in $\stackrel{0}{\triangle}$ the Gram stain or grew on culture. There was no significant difference between the density of growth obtained from immediate or delayed culture after biopsies had been stored at $4^{\circ} \mathrm{C}$ for up to five hours. 
There was a remarkable correlation between active chronic gastritis and the presence of spiral bacteria. These bacteria were found, either histologically or microbiologically, in 60 of 103 biopsies ( 44 of 80 patients): in 47 of 51 biopsies showing active chronic gastritis; eight of 23 showing chronic gastritis; one of 16 with "normal" mucosa; and four of 13 duodenal or oesophageal biopsies, all four of which showed gastric metaplasia and active inflammation. The negativity of the four biopsies from patients with active gastritis may have been related to the use of cimetidine. Nine biopsies from 26 patients with gastric ulcer showed $C$ pyloridis and an identical number of biopsies showed the organism in 12 patients with duodenal ulcer.

\section{DENSITY OF GROWTH}

The Figure shows the growth of $C$ pyloridis from one biopsy, which had been divided in half and one half minced and the other half ground. Seven other positive biopsies were similarly treated, and five gave noticeably more colonies after the specimen had been ground than after it had been minced.

Our culture methods yielded an abundant or moderate growth of $C$ pyloridis in $62 \%$ of positive specimens. In four specimens bacteria were cultured when they were not seen on Gram staining.

\section{VARIATIONS IN SOLID MEDIA}

Plates were kept for six to 19 days at room temperature $\left(24^{\circ} \mathrm{C}\right)$ in a closed plastic box in which the relative humidity was $92 \%$. The 15 positive specimens plated in parallel on freshly poured and older plates gave the same density of growth on both.

Specimens plated in parallel on whole blood agar with $1 \%$ Isovitalex or FBP supplement, yielded $C$ pyloridis on 11 occasions with Isovitalex but only seven with FBP supplement, six of which yielded a lighter culture. Incorporation of the components of FBP supplement into solid media indicated that sodium metabisulphite inhibited $C$ pyloridis in solid media.

\section{VARIATIONS IN CONCENTRATIONS OF ANTIBIOTICS}

The standard medium contained vancomycin $3 \mathrm{mg} / \mathrm{l}$ and nalidixic acid $10 \mathrm{mg} / \mathrm{l}$. When a medium without antibiotics was plated in parallel with this the standard medium yielded 29 isolates of $C$ pyloridis whereas the matching plates without antibiotics gave only 24 cultures. The five other matching plates all showed a moderate or heavy growth of contaminants, which occurred in $83 \%$ of the plates without antibiotics. On the standard medium a moderate or heavy growth of contaminants occurred in $28 \%$, and in two of these, although the Gram stain showed spiral bacteria, $C$ pyloridis was not cultured. Medium containing vancomycin $6 \mathrm{mg} / 1$, nalidixic acid $20 \mathrm{mg} / \mathrm{l}$, and amphotericin $2 \mathrm{mg} / \mathrm{l}$ was tested in parallel, and 22 isolates of $C$ pyloridis were obtained on this medium and the standard medium; the density of growth of $C$ pyloridis on both media was the same. With the higher concentration of antibiotics, contaminants were scanty and on only $18 \%$ of the plates. Whenever spiral bacteria were seen in the Gram stain $C$ pyloridis was cultured. An even higher concentration of antibiotics: (vancomycin $20 \mathrm{mg} / \mathrm{l}$, nalidixic acid $30 \mathrm{mg} / \mathrm{l}$, and amphotericin $4 \mathrm{mg} / \mathrm{l}$ ) inhibited all contaminants, but four of nine isolates were also inhibited. In three of the five positive cultures the growth was heavier on the standard medium than on the medium with these higher concentrations of antibiotics. We concluded that the most satisfactory medium contained vancomycin 6 $\mathrm{mg} / \mathrm{l}$, nalidixic acid $20 \mathrm{mg} / \mathrm{l}$, and amphotericin 2 $\mathrm{mg} / \mathrm{l}$, which allowed contaminants to be inhibited but not $C$ pyloridis.

The density of growth on lysed blood agar and the size of the colonies were less than on whole blood agar for four of the 10 isolates of $C$ pyloridis grown on plates inoculated in parallel.

\section{INCUBATION ATMOSPHERES}

The preferred atmosphere, obtained by evacuation to $220 \mathrm{~mm} \mathrm{Hg}$ and replacement with anaerobic gas mixture, was tested in parallel with the campylobacter gas mixture. The inoculum obtained from 33 ground specimens gave 15 positive cultures with each atmosphere, all from matching pairs, but showed a scantier growth with two biopsies in the campylobacter gas mixture. For the 13 minced specimens the six positive cultures grew equally well in both atmospheres.

Specimens cultured in parallel in the carbon dioxide incubator and the anaerobic jar mixture gave 16 positive cultures in the anaerobic jar mixture but only 13 in the carbon dioxide incubator; eight of these 13 cultures produced a scantier growth in the carbon dioxide incubator than in the anaerobic jar mixture.

\section{CONTAMINATION OF ENDOSCOPE WITH Campylobacter sputorum}

In one of our patients $C$ pyloridis was isolated from the antrum, but another biopsy from the oesophagus also yielded a growth of spiral bacteria, although none was seen with Gram stain. On subculture growth appeared after only one day of incubation, and biochemical tests gave a heterogeneous result that was clarified only by extensive subculturing. The isolate from the oesophagus was finally confirmed as $C$ sputorum, and we suspect that the 


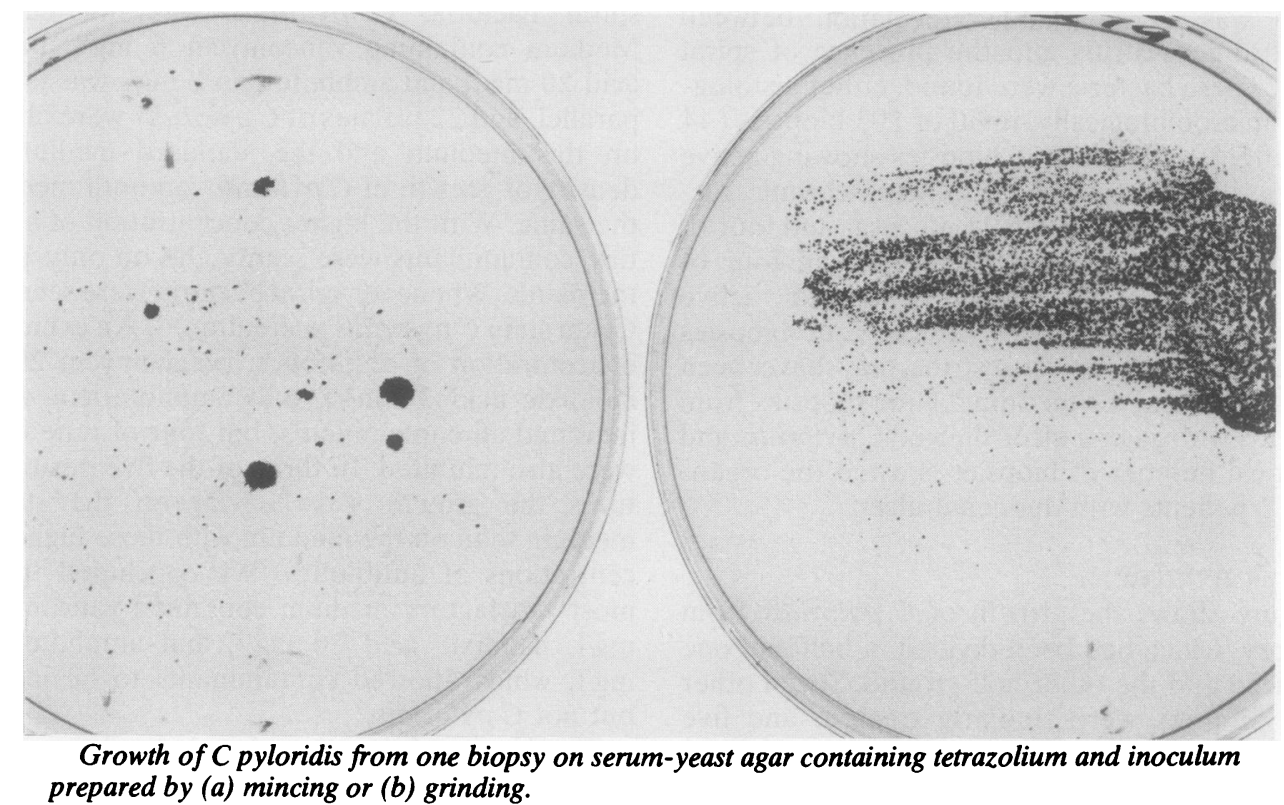

original isolate had been contaminated by $C$ pyloridis.

\section{Discussion}

Grinding the biopsy tissues with a ground glass grinder usually yielded a heavier, more uniform culture than mincing the tissue with knives (Figure). Such uniformity would be unlikely for the method described by Jones et al, ${ }^{5}$ who "rubbed" the biopsy on the surface of the blood agar plate. With a consistently uniform inoculum primary isolation of $C$ pyloridis on different media should be the most sensitive method of comparing media and incubation atmospheres. Provided biopsies were kept at $4^{\circ} \mathrm{C}$, delay for up to five hours did not seem to affect the isolation of $C$ pyloridis.

We were impressed by the fact that $C$ pyloridis seems to be found in the gastric mucosa in a patchy distribution. Biopsies taken close together sometimes show an absence of spiral bacteria in one but an abundance in the other. Most biopsies showed a somewhat patchy distribution of bacteria. This may partly explain the instances when either culture or histology, but not both, was positive.

The most satisfactory medium was brain-heart infusion agar with $7 \%$ horse blood, $1.0 \%$ Isovitalex, vancomycin $6 \mathrm{mg} / \mathrm{l}$, nalidixic acid $20 \mathrm{mg} / \mathrm{l}$, and amphotericin $2 \mathrm{mg} / \mathrm{l}$. Isolation of $C$ pyloridis was excellent, and contaminants were inhibited almost completely. Concentrations of antibiotics higher than these inhibited $C$ pyloridis. FBP supplement inhibited some isolates of $C$ pyloridis, and we determined that the component responsible was sodium metabisulphite. Incubation in a carbon dioxide incubator is not recommended for primary isolation; this contradicts a previous report. ${ }^{2}$

Cimetidine may have a useful antibacterial action against $C$ pyloridis. In a separate study, to be published elsewhere, on the susceptibility of $C$ pyloridis to antibiotics and antiulcer agents we found that the minimum inhibitory concentration of cimetidine against $C$ pyloridis was $4 \mathrm{mg} / \mathrm{l}$. Isolation of $C$ pyloridis from patients receiving cimetidine in the present study was low. From 35 biopsies from patients taking cimetidine there were 11 positive cultures $(31 \%)$ (from nine of 25 patients), and from the 68 other biopsies there were 37 positive cultures (54\%) ( 29 of 55 patients) $(\mathrm{p}=0.022$, Fisher's exact method). Three of the four patients with active chronic gastritis but with no apparent bacteria were receiving cimetidine. Eight of 11 of the positive cultures from patients receiving cimetidine, however, gave quite a heavy growth. The clinical importance of these findings is uncertain, and further investigation is required.

This study confirms previous observations ${ }^{1}$ that $C$ pyloridis is closely associated with active chronic gastritis; in our study $\boldsymbol{C}$ pyloridis was detected on only one biopsy that appeared normal histologically, and the patient showed active chronic gastritis in a second specimen. Jones et $\mathrm{al}^{\mathbf{5}}$ found a close association between $C$ pyloridis and both types of gastritis which they described as "superficial" or "atrophic". 
Other studies have also reported a close association of $C$ pyloridis with gastritis. ${ }^{36}$ The clinical importance of $C$ pyloridis will be clarified if histopathologists use similar nomenclature to describe varying forms of gastritis. Most histopathologists do not seem to differentiate between "chronic" and "active chronic" gastritis, conditions which have been clearly defined by Whitehead ${ }^{4}$ and Marshall and Warren. ${ }^{1}$ We found a pronounced difference between the detection of $C$ pyloridis in active chronic gastritis $(92 \%)$ and chronic gastritis $(35 \%)$.

Finally, we must mention that although we have proposed the name $C$ pyloridis for these spiral bacteria from the stomach, other studies of ours on the fatty acids and ultrastructure of $C$ pyloridis ${ }^{7}$ and the protein patterns reported by Pearson et al ${ }^{8}$ suggest that these bacteria do not belong to the genus Campylobacter.

We thank Dr B Marshall for technical advice, Dr D Annear for the Figure, Mrs Pam Blake and Miss Julia Burton for technical help, and Mrs Faye Coverley for secretarial help.
References

' Marshall BJ, Warren JR. Unidentified curved bacilli in the stomach of patients with gastritis and peptic ulceration. Lancet 1984;i:1311-4.

${ }^{2}$ Marshall BJ, Royce H, Annear DI, et al. Original isolation of Campylobacter pyloridis from human gastric mucosa. Microbios $1984 ; 25$ : 83-8.

${ }^{3}$ McNulty CAM, Watson DM. Spiral bacteria of the gastric antrum. Lancet 1984; i: 1067-8.

${ }^{4}$ Whitehead R, Truelove SC, Gear MWL. The histological diagnosis of chronic gastritis in fibre optic gastroscope biopsy specimens. J Clin Pathol 1972;25:1-11.

s Jones DM, Lessells AM, Eldridge J. Campylobacter like organisms on the gastric mucosa: culture, histological, and serological studies. J Clin Pathol 1984;37:1002-6.

${ }^{6}$ Langenberg ML, Tytgat GNJ, Schipper MEI, Rietra PJGM, Zanen HC. Campylobacter-like organisms in the stomach of patients and healthy individuals. Lancet 1984;i: 1348 .

' Goodwin CS, McCulloch RK, Armstrong JA, Wee SH. Unusual cellular fatty acids, and distinctive ultrastructure in a new spiral bacterium (Campylobacter pyloridis) from the human gastric mucosa. J Med Microbiol 1985; 19:257-67.

${ }^{8}$ Pearson AD, Bamforth J, Booth L, et al. Polyacrylamide gel electrophoresis of spiral bacteria from the gastric antrum. Lancet 1984; i: 1349-50.

Requests for reprints to: Professor CS Goodwin, Department of Microbiology, Royal Perth Hospital, Box X2213, GPO, Perth, Western Australia 6001. 